\title{
Extravascular manifestations of Takayasu arteritis: focusing on the features shared with spondyloarthritis
}

\author{
Oh Chan Kwon', Sang-Won Lee ${ }^{2}$, Yong-Beom Park², Ji Seon Oh³, Sang Hoon Lee ${ }^{4}$, Seokchan Hong ${ }^{1}$, \\ Chang-Keun Lee ${ }^{1}$, Bin Yoo ${ }^{1}$ and Yong-Gil Kim ${ }^{1 *}$ (D)
}

\begin{abstract}
Background: Takayasu arteritis (TAK) is a systemic disease characterized by large vessel involvement. Although the vascular characteristics of TAK are well characterized, there is no well-organized study demonstrating the extravascular manifestations of TAK. We aimed to evaluate the characteristics of extravascular manifestations of TAK, and to identify the association between vascular and extravascular manifestations of TAK.

Methods: TAK patients from two independent cohorts between January 2012 and October 2017 were included in the study. Patient characteristics were retrospectively collected from the electronic dataset. The computed tomography scans of all subjects were reviewed to evaluate the pattern of vascular involvement and presence of sacroiliitis. Clinical findings including uveitis, skin lesions, oral ulcers, arthritis, and inflammatory bowel disease (IBD) were reviewed. Logistic regression analysis was performed to evaluate the association between vascular and extravascular manifestations.
\end{abstract}

Results: For the 268 TAK patients, the mean age at diagnosis was $41.2 \pm 14.2$ years and $88.1 \%$ were female. The extravascular manifestation of TAK was observed in $19.0 \%$ of patients, the most common being arthritis including sacroiliitis (11.9\%) followed by recurrent oral ulcers (8.6\%) and IBD (2.6\%). A multivariate logistic regression analysis revealed type IIB vascular involvement (adjusted odds ratio (OR) 2.956, 95\% confidence interval (Cl) 1.337-6.537, $p=0.007$ ) and the erythrocyte sedimentation rate (ESR) (adjusted OR 1.014, 95\% Cl 1.003-1.025, $p=0.012$ ) as significantly associated with the presence of axial and peripheral arthritis.

Conclusions: Extravascular manifestations of TAK were observed in up to one-fifth of patients. The most common extravascular manifestation was arthritis, which was associated with a type IIB vascular involvement pattern and a high ESR.

Keywords: Takayasu arteritis, Extravascular manifestation, Arthritis

\section{Background}

Takayasu arteritis (TAK) is a systemic vasculitis mainly involving the aorta and its major branches and can cause occlusive or aneurysmal degeneration [1]. The prevalence of TAK in Japan was estimated at 40 per 1 million of population, with a female predominance [2]. The prevalence of TAK in European studies is lower than

\footnotetext{
* Correspondence: bestmd2000@amc.seoul.kr

${ }^{1}$ Division of Rheumatology, Department of Internal Medicine, University of Ulsan, College of Medicine, Asan Medical Center, 88 Olympic-ro 43-gil, Songpa-gu, Seoul 05505, South Korea

Full list of author information is available at the end of the article
}

that in Japan, being 4.7-13.2 per 1 million of population [3-5].

Despite this rarity, based on a number of previous studies [1, 6-11], knowledge regarding TAK has much improved since its first report in Japan in 1908 [12]. In particular, the vascular manifestations of TAK have been well reported in previous studies [1, 6-11]. Although there might be some discrepancies among different ethnic populations, the largest scale observational study conducted in Japan [1] reported that local symptoms and findings attributable to vascular involvement were most commonly observed in the cervicobrachial area.

(c) The Author(s). 2018 Open Access This article is distributed under the terms of the Creative Commons Attribution 4.0 International License (http://creativecommons.org/licenses/by/4.0/), which permits unrestricted use, distribution, and 
Accordingly, the majority of the patients exhibited vascular involvements of the aortic arch or its major branches, which supply the cervicobrachial area. Furthermore, the most common type of angiographic involvement according to Hata's classification [13] was type I (branches of the aortic arch).

Although the vascular manifestations of TAK are well known, the extravascular manifestations of TAK remain unclear. Some recent studies have addressed spondyloarthritis (SpA) [14, 15] and inflammatory bowel disease (IBD) $[16,17]$ in TAK patients. However, only sporadic case reports regarding other extravascular manifestations such as erythema nodosum [18-20] and uveitis [21, 22] have been reported. Moreover, peripheral arthritis has occasionally been observed in TAK patients, but data concerning these manifestations are not well established. Therefore, we aimed to identify the characteristics of extravascular manifestations of TAK. Furthermore, we evaluated the association between vascular and extravascular manifestations of TAK.

\section{Methods}

\section{Study population}

Two independent cohorts from two tertiary referral hospitals in South Korea were included. All study subjects were diagnosed with TAK and encoded M314 according to the International Statistical Classification of Diseases and Related Health Problems, Tenth Revision (ICD-10) between January 2012 and October 2017. All patients met the 1990 American College of Rheumatology (ACR) classification criteria for TAK [23]. Computed tomography $(\mathrm{CT})$ scans encompassing the entire aorta and its branches as a diagnostic evaluation were present for all patients. Patients who only underwent localized imaging work-up such as carotid duplex sonography or neck angiography were excluded.

Electronic medical records of the study subjects were reviewed, and information pertaining to age, sex, the presence of hypertension (HTN), clinical symptoms and signs, laboratory data at initial presentation including erythrocyte sedimentation rate (ESR) and C-reactive protein (CRP), and imaging data were collected. Regarding clinical symptoms and signs, those attributable to vascular involvement such as claudication, decreased pulse, and blood pressure difference $>10 \mathrm{mmHg}$ between arms, bruit, and carotidynia were reviewed. The CT scans were utilized to assess the distribution of vascular lesions and categorize them according to Hata's classification [13].

This study was approved by the Institutional Review Board of Asan Medical Center in Seoul, South Korea (IRB No. 2017-0857). The requirement for informed consent was waived due to the retrospective nature of the study.

\section{Extravascular manifestations}

The presence of peripheral arthritis, axial arthritis (sacroiliitis), recurrent oral ulcers, erythema nodosum, IBD (Crohn's disease (CD) and ulcerative colitis (UC)), and uveitis were determined from the electronic medical records. A radiologist confirmed the presence of sacroiliitis from the CT scans that were taken for the diagnostic work-up of TAK.

For patients with peripheral arthritis, the number and distribution of joint involvements and positivity of rheumatoid factor (RF), anti-cyclic citrullinated peptide (anti-CCP) antibody, and antinuclear antibody (ANA) (if the laboratory test was performed) were reviewed. The number of joint involvements was classified as monoarthritis (1 joint involved), oligoarthritis (2-3 joints involved), and polyarthritis ( $\geq 4$ joints involved). The distribution of joint involvement was assessed by the size (small joints, large joints, or both), symmetry, and location (upper extremities, lower extremities, or both) of the joints involved. For patients with sacroiliitis, positivity of HLA-B27 (if the laboratory test was performed) and whether they fulfilled the radiologic 1984 modified New York criteria [24] were reviewed.

\section{Statistical analysis}

We described both vascular and extravascular manifestations. Continuous variables were expressed as the mean \pm standard deviation (SD) and median (interquartile range (IQR)) for a normal and a non-normal distribution, respectively. Categorical variables were expressed as number (\%). To evaluate the association between vascular and extravascular manifestations, we performed logistic regression analysis. Univariate analysis was performed for each variable, and variables determined statistically significant $(p<0.05)$ were included in a multivariate analysis.

\section{Results}

\section{Baseline characteristics}

During the study period, 268 TAK patients (185 and 83 from each cohort, respectively) with the ICD-10 code M314 who met the 1990 ACR classification criteria for TAK [23] were identified.

The mean age of the study population was $41.2 \pm$ 14.2 years. The patients were predominantly female (88.1\%). A blood pressure difference of more than $10 \mathrm{mmHg}$ between both arms, decreased pulse, bruit, HTN, claudication, and carotidynia were observed in $84.1 \%, 56.7 \%, 45.8 \%, 44.8 \%, 33.9 \%$, and $14.4 \%$ patients, respectively. The median ESR result was $24.0 \mathrm{~mm} / \mathrm{h}$ (IQR 13.0-46.0), and the median CRP serum concentration was $0.17 \mathrm{mg} / \mathrm{dl}$ (IQR 0.10-0.70) (Table 1). 
Table 1 Baseline characteristics of the 268 Takayasu arteritis patients

\begin{tabular}{|c|c|}
\hline Characteristic & $N=268$ \\
\hline Age (years), mean $( \pm S D)$ & $41.2( \pm 14.2)$ \\
\hline Female & $236(88.1 \%)$ \\
\hline Hypertension & $120(44.8 \%)$ \\
\hline Claudication $\left(N^{a}=218\right)$ & $74(33.9 \%)$ \\
\hline Decreased pulse $\left(N^{\mathrm{a}}=203\right)$ & $115(56.7 \%)$ \\
\hline Blood pressure difference $>10 \mathrm{mmHg}\left(N^{\mathrm{a}}=239\right)$ & $201(84.1 \%)$ \\
\hline Bruit $\left(N^{a}=203\right)$ & $93(45.8 \%)$ \\
\hline Carotidynia $\left(N^{a}=201\right)$ & $29(14.4 \%)$ \\
\hline ESR (mm/h), median (IQR) & $24.0(13.0-46.0)$ \\
\hline CRP (mg/dl), median (IQR) & $0.17(0.10-0.70)$ \\
\hline \multicolumn{2}{|l|}{ Vessel involvement } \\
\hline Common carotid artery & $176(65.7 \%)$ \\
\hline Subclavian artery & $170(63.4 \%)$ \\
\hline Ascending aorta & $84(31.3 \%)$ \\
\hline Aortic arch & $100(37.3 \%)$ \\
\hline Descending aorta & $151(56.3 \%)$ \\
\hline Abdominal aorta & $124(46.3 \%)$ \\
\hline Renal artery & $54(20.1 \%)$ \\
\hline \|liac artery & $30(11.2 \%)$ \\
\hline Pulmonary artery & $30(11.2 \%)$ \\
\hline \multicolumn{2}{|l|}{ Hata's classification } \\
\hline Type I & $54(20.1 \%)$ \\
\hline Type IIA & 23 (8.6\%) \\
\hline Type IIB & 55 (20.5\%) \\
\hline Type III & 10 (3.7\%) \\
\hline Type IV & $6(2.2 \%)$ \\
\hline Type V & $120(44.8 \%)$ \\
\hline
\end{tabular}

Table 2 Extravascular manifestations of Takayasu arteritis

\begin{tabular}{ll}
\hline Manifestation & $N=268$ \\
\hline At least one extravascular manifestation present & $51(19.0 \%)$ \\
Arthritis & $32(11.9 \%)$ \\
$\quad$ Axial arthritis (sacroiliitis) & $19(7.1 \%)$ \\
$\quad$ Peripheral arthritis & $16(6.0 \%)$ \\
Recurrent oral ulcers & $23(8.6 \%)$ \\
Inflammatory bowel disease & $7(2.6 \%)$ \\
$\quad$ Crohn's disease & $4(1.5 \%)$ \\
$\quad$ Ulcerative colitis & $3(1.1 \%)$ \\
Erythema nodosum $^{\text {Uveitis }}{ }^{\mathrm{a}}$ & $4(1.5 \%)$ \\
\hline
\end{tabular}

Data presented as $n$ (\%)

${ }^{\mathrm{a}}$ Both patients had unilateral anterior uveitis

\section{Patterns of vessel involvement}

The most frequently involved vessel was the common carotid artery (65.7\%), followed by the subclavian artery (63.4\%) and the descending aorta (56.3\%). The least involved vessels were the iliac and pulmonary arteries (both 11.2\%). The most common pattern of vessel involvement according to Hata's classification [13] was type V (44.8\%) (Table 1 ).

\section{Extravascular manifestations}

Of the 268 patients, $19.0 \%$ displayed at least one extravascular manifestation, the most common being arthritis, followed by recurrent oral ulcers, IBD, and erythema nodosum (11.9\%, 8.6\%, 2.6\%, and 1.5\%. respectively). Uveitis (unilateral anterior uveitis) was infrequently detected (0.7\%). The 32 arthritic patients comprised 19 with sacroiliitis and 16 with peripheral arthritis (Table 2).

As shown in Table 3, of the 19 patients with sacroiliitis, the majority were female $(89.5 \%)$ and HLA-B27 negative (85.7\%). The 1984 modified New York criteria [24] were met by $68.4 \%$ of these patients, and $15.8 \%$ exhibited peripheral arthritis. Enthesitis, IBD, and uveitis were present in one patient each. While type $\mathrm{V}$ vessel involvement was the most common in the total study population, type IIB was most frequently observed in the patients with sacroiliitis

Table 3 Characteristics of the 19 Takayasu arteritis patients with axial arthritis (sacroiliitis)

\begin{tabular}{|c|c|}
\hline Characteristic & $N=19$ \\
\hline Age (years), mean ( \pm SD) & $\begin{array}{l}38.9( \pm \\
14.9)\end{array}$ \\
\hline \multicolumn{2}{|l|}{ Sex } \\
\hline Male & $2(10.5 \%)$ \\
\hline Female & 17 (89.5\%) \\
\hline HLA-B27 $\left(N^{a}=7\right)$ & $1(14.3 \%)$ \\
\hline $\begin{array}{l}\text { Sacroiliitis meeting } 1984 \text { modified New York criteria }{ }^{\text {b for }} \\
\text { AS }\end{array}$ & $13(68.4 \%)$ \\
\hline Peripheral arthritis & $3(15.8 \%)$ \\
\hline Enthesitis & $1(5.3 \%)$ \\
\hline Inflammatory bowel disease & $1(5.3 \%)$ \\
\hline Uveitis & $1(5.3 \%)$ \\
\hline \multicolumn{2}{|l|}{ Hata's classification } \\
\hline Type I & $3(15.8 \%)$ \\
\hline Type ॥A & $2(10.5 \%)$ \\
\hline Type IIB & $7(36.8 \%)$ \\
\hline Type III & $1(5.3 \%)$ \\
\hline Type IV & $0(0.0 \%)$ \\
\hline Type V & $6(31.6 \%)$ \\
\hline
\end{tabular}



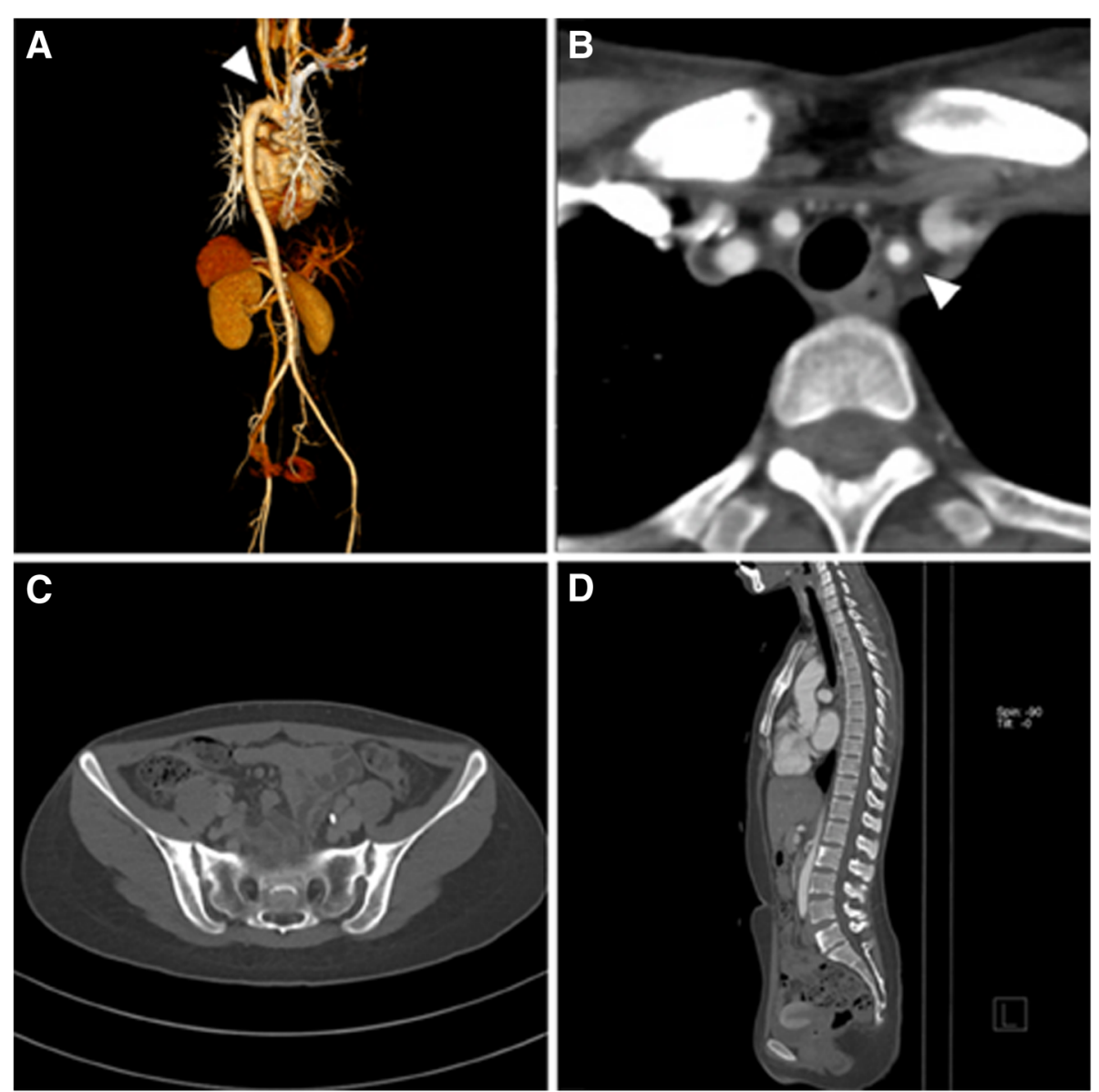

Fig. 1 Computed tomography (CT) images of Takayasu arteritis (TAK) patient who exhibited sacroiliitis as an extravascular manifestation. Female patient, 29 years old, negative for HLA-B27. a Complete occlusion in left subclavian artery (arrowhead). b Concentric wall thickening in left common carotid artery (arrowhead). c Sclerosis in both sacroiliac joints and erosion with joint space widening suggesting grade III sacroiliitis. d Vertebral corner inflammations, especially in lumbar spines (L2 and L5)

(36.8\%). Representative images of a TAK patient with sacroiliitis are presented in Fig. 1.

The characteristics of the 16 patients with peripheral arthritis are presented in Table 4. Monoarthritis, oligoarthritis, and polyarthritis were observed in $37.5 \%, 43.8 \%$, and $18.8 \%$ of patients, respectively. Regarding joint distribution, large joint involvement was most common (62.5\%), and the shoulder joint most frequently affected. The majority of patients exhibited asymmetric joint involvement (87.5\%). The locations of involved joints were approximately evenly distributed between the upper extremities, the lower extremities, and both the upper and lower extremities together. RF was positive in $9.1 \%$, and none of the patients were positive for anti-CCP antibody or ANA. The most common vessel involvement was type IIB (50\%), which is concordant with that of the study subjects with sacroiliitis.

\section{Vascular manifestations associated with arthritis}

Logistic regression analysis was performed to evaluate vascular manifestations associated with arthritis in TAK patients (Table 5). On univariate analysis, ESR, CRP, and type IIB vessel involvement were significantly associated with arthritis $(p=0.007, p=0.027$, and $p=0.004$, respectively). Type $\mathrm{V}$ vessel involvement was inversely associated with arthritis $(p=0.048)$. On multivariate analysis, ESR $(p=0.012)$ and type IIB $(\mathrm{p}=0.007)$ remained significant.

\section{Discussion}

In this study, we determined that extravascular manifestations of TAK were not rare, with a prevalence of $19.0 \%$. In particular, arthritis $(11.9 \%)$ was the most common extravascular manifestation. To the best of our knowledge, this is the first study describing the extravascular manifestations of TAK in detail.

Sacroiliitis was present in $7.1 \%$ TAK patients. Considering that the global prevalence of SpA is approximately $1 \%$ [25], the proportion of TAK patients with sacroiliitis appears high. Although not clear to date, there might be a shared genetic background between TAK and sacroiliitis, 
Table 4 Characteristics of the 16 Takayasu arteritis patients with peripheral arthritis

\begin{tabular}{|c|c|}
\hline Characteristic & $N=16$ \\
\hline Age (years), mean ( $\pm \mathrm{SD})$ & $41.6( \pm 14.7)$ \\
\hline \multicolumn{2}{|l|}{ Sex } \\
\hline Male & $2(12.5 \%)$ \\
\hline Female & $14(87.5 \%)$ \\
\hline \multicolumn{2}{|l|}{ Number of joints involved } \\
\hline Monoarthritis (1 joint) & $6(37.5 \%)$ \\
\hline Oligoarthritis (2-3 joints) & $7(43.8 \%)$ \\
\hline Polyarthritis ( $\geq 4$ joints) & $3(18.8 \%)$ \\
\hline \multicolumn{2}{|l|}{ Distribution of joint involvement } \\
\hline \multicolumn{2}{|l|}{ Size } \\
\hline Small joints & $3(18.8 \%)$ \\
\hline Large joints $^{a}$ & $10(62.5 \%)$ \\
\hline Small and large joints & $3(18.8 \%)$ \\
\hline \multicolumn{2}{|l|}{ Symmetry } \\
\hline Symmetric & $2(12.5 \%)$ \\
\hline Asymmetric & $14(87.5 \%)$ \\
\hline \multicolumn{2}{|l|}{ Location } \\
\hline Upper extremities & $6(37.5 \%)$ \\
\hline Lower extremities & $5(31.3 \%)$ \\
\hline Upper and lower extremities & $5(31.3 \%)$ \\
\hline $\operatorname{RF}\left(N^{b}=11\right)$ & $1(9.1 \%)$ \\
\hline Anti-CCP antibody $\left(N^{b}=11\right)$ & $0(0.0 \%)$ \\
\hline ANA $\left(N^{b}=11\right)$ & $0(0.0 \%)$ \\
\hline \multicolumn{2}{|l|}{ Hata's classification } \\
\hline Type I & $2(12.5 \%)$ \\
\hline Type IIA & $1(6.3 \%)$ \\
\hline Type ॥B & $8(50.0 \%)$ \\
\hline Type III & $1(6.3 \%)$ \\
\hline Type IV & $1(6.3 \%)$ \\
\hline Type V & $3(18.8 \%)$ \\
\hline
\end{tabular}

Data presented as $n$ (\%) unless stated otherwise

$S D$ standard deviation, $R F$ rheumatoid factor, $C C P$ cyclic citrullinated peptide, ANA antinuclear antibody

${ }^{a}$ Most commonly involved was the shoulder joint

${ }^{\mathrm{b}}$ Patients with missing data excluded

which could play a central role in their co-occurrence. Further study regarding this issue could aid in elucidating the pathophysiologic background of these diseases. We discovered that the characteristics of sacroiliitis in TAK differed from SpA patients in general, being predominantly female $(89.5 \%)$ and exhibiting a low incidence of HLA-B27 positivity (14.3\%) [25-27]. This finding is consistent with a previous study [15] that also demonstrated female predominance and low HLA-B27 positivity. Furthermore, the presence of SpA features other than sacroiliitis in these patients was relatively low (peripheral
Table 5 Vascular manifestations associated with arthritis in Takayasu arteritis

\begin{tabular}{|c|c|c|c|}
\hline Characteristic & Unadjusted OR & $95 \% \mathrm{Cl}$ & $P$ value \\
\hline \multicolumn{4}{|l|}{ Univariate analysis } \\
\hline ESR & 1.015 & $1.004-1.025$ & $0.007^{*}$ \\
\hline CRP & 1.123 & $1.013-1.245$ & $0.027^{*}$ \\
\hline Claudication & 0.687 & $0.275-1.718$ & 0.422 \\
\hline Decreased pulse & 0.816 & $0.342-1.946$ & 0.646 \\
\hline BP difference $>10 \mathrm{mmHg}$ & 1.657 & $0.474-5.792$ & 0.429 \\
\hline Bruit & 1.096 & $0.459-2.613$ & 0.837 \\
\hline Carotidynia & 0.877 & $0.243-3.163$ & 0.841 \\
\hline Common carotid artery & 1.658 & $0.713-3.853$ & 0.240 \\
\hline Subclavian artery & 2.241 & $0.931-5.394$ & 0.072 \\
\hline Ascending aorta & 1.844 & $0.869-3.913$ & 0.111 \\
\hline Aortic arch & 1.567 & $0.745-3.297$ & 0.236 \\
\hline Descending aorta & 2.156 & $0.957-4.857$ & 0.064 \\
\hline Abdominal aorta & 0.486 & $0.221-1.072$ & 0.074 \\
\hline Renal artery & 1.126 & $0.459-2.761$ & 0.795 \\
\hline Iliac artery & 0.230 & $0.030-1.751$ & 0.156 \\
\hline Pulmonary artery & 0.495 & $0.112-2.186$ & 0.354 \\
\hline Type I & 0.707 & $0.259-1.930$ & 0.498 \\
\hline Type IIA & 1.117 & $0.313-3.994$ & 0.865 \\
\hline Type ॥B & 3.160 & $1.448-6.897$ & $0.004^{*}$ \\
\hline Type III & 0.814 & $0.100-6.643$ & 0.847 \\
\hline Type IV & 1.490 & $0.169--13.177$ & 0.720 \\
\hline Type V & 0.441 & $0.196-0.992$ & $0.048^{*}$ \\
\hline \multicolumn{4}{|l|}{ Multivariate analysis } \\
\hline ESR & 1.014 & $1.003-1.025$ & $0.012^{*}$ \\
\hline CRP & 1.052 & $0.911-1.215$ & 0.489 \\
\hline Type IIB & 2.956 & $1.337-6.537$ & $0.007^{*}$ \\
\hline Type V & 0.634 & $0.243-1.652$ & 0.351 \\
\hline
\end{tabular}

OR odds ratio, $C l$ confidence interval, ESR erythrocyte sedimentation rate, $C R P$ $C$-reactive protein, $B P$ blood pressure

*Value considered significant $(p<0.05)$

arthritis $15.8 \%$, enthesitis 5.3\%, uveitis 5.3\%, IBD 5.3\%) compared to SpA patients in general (peripheral arthritis 39.8-58.0\%, enthesitis $37.8-50.0 \%$, uveitis $8.5-27.0 \%$, IBD $1.8-11.0 \%$ ) [28]. Considering that aortitis is one of the cardiovascular manifestations observed in ankylosing spondylitis and other forms of SpA [29], it can be challenging to differentiate TAK patients with sacroiliitis from SpA patients with aortitis. The aforementioned differences in the characteristics of sacroiliitis between these two patient types could provide clues in distinguishing one from another.

Peripheral arthritis was observed in $6.0 \%$ of TAK patients. This manifestation was characterized by an asymmetric oligoarthritis pattern, mostly involving the large joints. This was similar to the pattern observed in SpA 
(asymmetric oligoarthritis with lower extremity predominance) [30] except that an even distribution between the upper and lower extremities was observed.

Interestingly, the most common type of vessel involvement in TAK patients with arthritis (axial and/or peripheral arthritis) was type IIB, differing from the total study population where type $\mathrm{V}$ was most frequently observed. Furthermore, in the multivariate logistic regression analysis evaluating the association between arthritis and vascular manifestations, type IIB was associated with arthritis approximately three times higher than nontype IIB. Therefore, TAK patients with type IIB should be carefully monitored for arthritis.

In our study, the prevalence of IBD (2.6\%) in TAK patients appeared low compared to previous reports (5.8$8.3 \%)[16,31]$. However, considering that the prevalence of CD and UC are $0.01 \%$ and $0.03 \%$, respectively, in the general Korean population [32], a prevalence of $2.6 \%$ IBD in our TAK patients is obviously higher than that of the general population. This is consistent with a previous study reporting a higher prevalence of IBD in TAK patients than that in the general population $[16,31]$.

Recurrent oral ulcers (8.6\%) were the second most common extravascular manifestation in our study, whereas erythema nodosum (1.5\%) and uveitis (0.7\%) were rarely observed. Recurrent oral ulcers, erythema nodosum, and monoarthritis or oligoarthritis are manifestations that are also observed in Behcet's disease, as well as inflammation of large vessels [33]. Thus, it may be confusing to distinguish TAK from Behcet's disease. However, a notable difference between TAK and Behcet's disease is the absence of genital ulcers. In our data, none of the TAK patients exhibited genital ulcers, which have the highest discriminatory value in the International Study Group for Behcet's Disease criteria [34]. Furthermore, occlusion or stenosis due to homogeneous concentric wall thickness favors TAK, whereas thrombotic occlusion or a solitary aneurysm is more likely in Behcet's disease [33].

The present study has some limitations. First, this study was retrospective. Although not many, there were some missing data concerning clinical symptoms and signs. Therefore, there might be other extravascular manifestations that we have not identified. Second, only Korean TAK patients were included, and other ethnic populations could display different results. Thus, further studies with subjects from different ethnic populations are required. Despite these limitations, considering that TAK is such a rare disease, our results are strengthened by the relatively large number of patients.

\section{Conclusions}

In summary, we have shown that extravascular manifestations of TAK are observed in up to one-fifth of TAK patients. The most common extravascular manifestation was arthritis (axial arthritis and peripheral arthritis), and Hata's type IIB pattern of vessel involvement and a high ESR were associated with the presence of arthritis. The presented results are meaningful in that they provide clinicians with a better understanding of the accompanying extravascular manifestations of this rare disease.

\section{Funding}

This work was supported by grant 2017-655 from the Asan Institute for Life Sciences, Asan Medical Center, South Korea.

Availability of data and materials

All data generated or analyzed during this study are included in this article.

\section{Authors' contributions}

OCK contributed to the design, acquisition of data, data analyses, data interpretation, and manuscript preparation. S-WL contributed to the acquisition of data, data interpretation, and manuscript preparation. Y-BP contributed to the acquisition of data, data interpretation, and manuscript preparation. JSO contributed to data analyses, data interpretation, and manuscript preparation. SHL contributed to data analyses, data interpretation, and manuscript preparation. SH contributed to the acquisition of data, data analyses, data interpretation, and manuscript preparation. C-KL contributed to the acquisition of data, data analyses, data interpretation, and manuscript preparation. BY contributed to the acquisition of data, data analyses, data interpretation, and manuscript preparation. Y-GK contributed to the study concept and design, acquisition of data, data interpretation, and manuscript preparation. All authors read and approved the final manuscript.

Ethics approval and consent to participate

This study was approved by the Institutional Review Board of Asan Medical Center in Seoul, South Korea (IRB No. 2017-0857).

Competing interests

The authors declare that they have no competing interests.

\section{Publisher's Note}

Springer Nature remains neutral with regard to jurisdictional claims in published maps and institutional affiliations.

\section{Author details}

'Division of Rheumatology, Department of Internal Medicine, University of Ulsan, College of Medicine, Asan Medical Center, 88 Olympic-ro 43-gil, Songpa-gu, Seoul 05505, South Korea. ${ }^{2}$ Division of Rheumatology, Department of Internal Medicine, Yonsei University College of Medicine, Seoul, South Korea. ${ }^{3}$ Clinical Research Center, University of Ulsan College of Medicine, Asan Medical Center, Seoul, South Korea. ${ }^{4}$ Department of Radiology and Research Institute of Radiology, University of Ulsan College of Medicine, Asan Medical Center, Seoul, South Korea.

Received: 9 April 2018 Accepted: 12 June 2018

Published online: 11 July 2018

\section{References}

1. Watanabe Y, Miyata T, Tanemoto K. Current clinical features of new patients with Takayasu arteritis observed from cross-country research in Japan: age and sex specificity. Circulation. 2015;132:1701-9. https://doi.org/10.1161/ circulationaha.114.012547.

2. Terao C, Yoshifuji H, Mimori T. Recent advances in Takayasu arteritis. Int J Rheum Dis. 2014;17:238-47. https://doi.org/10.1111/1756-185x.12309.

3. Mohammad AJ, Mandl T. Takayasu arteritis in southern Sweden. J Rheumatol. 2015;42:853-8. https://doi.org/10.3899/jrheum.140843.

4. Dreyer L, Faurschou M, Baslund B. A population-based study of Takayasu's arteritis in eastern Denmark. Clin Exp Rheumatol. 2011;29:S40-2.

5. Watts R, Al-Taiar A, Mooney J, Scott D, Macgregor A. The epidemiology of Takayasu arteritis in the UK. Rheumatology (Oxford). 2009;48:1008-11. https://doi.org/10.1093/rheumatology/kep153. 
6. Ueda H, Morooka S, Ito I, Yamaguchi H, Takeda T. Clinical observation of 52 cases of aortitis syndrome. Jpn Heart J. 1969;10:277-88.

7. Jain S, Kumari S, Ganguly NK, Sharma BK. Current status of Takayasu arteritis in India. Int J Cardiol. 1996;54((Suppl)):S111-6.

8. Zheng D, Fan D, Liu L. Takayasu arteritis in China: a report of 530 cases. Heart Vessels Suppl. 1992;7:32-6.

9. Park YB, Hong SK, Choi K, Sohn DW, Oh BH, Lee MM, et al. Takayasu arteritis in Korea: clinical and angiographic features. Heart Vessels Suppl. 1992;7:55-9.

10. Kerr GS, Hallahan CW, Giordano J, Leavitt RY, Fauci AS, Rottem M, et al. Takayasu arteritis. Ann Intern Med. 1994;120:919-29.

11. Lupi-Herrera E, Sanchez-Torres G, Marcushamer J, Mispireta J, Horwitz S, Vela JE. Takayasu's arteritis. Clinical study of 107 cases. Am Heart J. 1977;93:94-103.

12. Numano F. The story of Takayasu arteritis. Rheumatology (Oxford). 2002;41:103-6.

13. Moriwaki R, Noda M, Yajima M, Sharma BK, Numano F. Clinical manifestations of Takayasu arteritis in India and Japan-new classification of angiographic findings. Angiology. 1997;48:369-79. https://doi.org/10.1177/ 000331979704800501.

14. Gan FY, Fei YY, Li MT, Wang Q, Xu D, Hou Y, et al. The characteristics of patients having ankylosing spondylitis associated with Takayasu's arteritis. Clin Rheumatol. 2014;33:355-8. https://doi.org/10.1007/s10067-013-2444-7.

15. Riviere E, Arnaud L, Ebbo M, Allanore Y, Claudepierre P, Dernis E, et al. Takayasu arteritis and spondyloarthritis: coincidence or association? A study of 14 cases. J Rheumatol. 2017;44:1011-7. https://doi.org/10.3899/ jrheum.160762.

16. Kilic L, Kalyoncu U, Karadag O, Akdogan A, Dogan I, Bilgen SA, et al. Inflammatory bowel diseases and Takayasu's arteritis: coincidence or association? Int J Rheum Dis. 2016;19:814-8. https://doi.org/10.1111/1756$185 \times 12837$.

17. Terao C, Matsumura T, Yoshifuji H, Kirino Y, Maejima Y, Nakaoka Y, et al. Takayasu arteritis and ulcerative colitis: high rate of co-occurrence and genetic overlap. Arthritis Rheumatol. 2015;67:2226-32. https://doi.org/10. 1002/art.39157.

18. Loetscher J, Fistarol S, Walker UA. Pyoderma gangrenosum and erythema nodosum revealing Takayasu's arteritis. Case Rep Dermatol. 2016;8:354-7. https://doi.org/10.1159/000452829.

19. Pascual-Lopez M, Hernandez-Nunez A, Aragues-Montanes M, Dauden E, Fraga J, Garcia-Diez A. Takayasu's disease with cutaneous involvement. Dermatology. 2004;208:10-5. https://doi.org/10.1159/000075039.

20. Gupta M, Singh K, Lehl SS, Bhalla M. Recurrent erythema nodosum: a red flag sign of hidden systemic vasculitis. BMJ Case Rep. 2013;2013 https://doi. org/10.1136/bcr-2013-009507.

21. McDonald MA, Ojaimi E, Favilla I. Anterior uveitis in a child with Takayasu's arteritis. Clin Exp Ophthalmol. 2004;32:336-9. https://doi.org/10.1111/j.14429071.2004.00828.x

22. Becker RW, Sohn RL, Poulik JM, Berguer R. Takayasu's arteritis presenting as uveitis in a 5-year-old girl. Ann Vasc Surg. 2005;19:258-62. https://doi.org/10. 1007/s10016-004-0178-3.

23. Arend WP, Michel BA, Bloch DA, Hunder GG, Calabrese LH, Edworthy SM, et al. The American College of Rheumatology 1990 criteria for the classification of Takayasu arteritis. Arthritis Rheum. 1990;33:1129-34.

24. van der Linden S, Valkenburg HA, Cats A. Evaluation of diagnostic criteria for ankylosing spondylitis. A proposal for modification of the New York criteria. Arthritis Rheum. 1984;27:361-8.

25. van Tubergen $A$. The changing clinical picture and epidemiology of spondyloarthritis. Nat Rev Rheumatol. 2015;11:110-8. https://doi.org/10. 1038/nrrheum.2014.181.

26. Rudwaleit M, Haibel H, Baraliakos X, Listing J, Marker-Hermann E, Zeidler H, et al. The early disease stage in axial spondylarthritis: results from the German Spondyloarthritis inception cohort. Arthritis Rheum. 2009;60:717-27. https://doi.org/10.1002/art.24483.

27. Taurog JD, Chhabra A, Colbert RA. Ankylosing spondylitis and axial spondyloarthritis. N Engl J Med. 2016;374:2563-74. https://doi.org/10.1056/ NEJMra1406182.

28. Sieper J, Poddubnyy D. Axial spondyloarthritis. Lancet. 2017:390:73-84. https://doi.org/10.1016/s0140-6736(16)31591-4.

29. Palazzi C, DA S, Lubrano E, Olivieri I. Aortic involvement in ankylosing spondylitis. Clin Exp Rheumatol. 2008;26:S131-4.
30. Amor B, Santos RS, Nahal R, Listrat V, Dougados M. Predictive factors for the longterm outcome of spondyloarthropathies. J Rheumatol. 1994;21:1883-7.

31. Gudbrandsson B, Molberg O, Garen T, Palm O. Prevalence, incidence, and disease characteristics of Takayasu arteritis by ethnic background: data from a large, population-based cohort resident in southern Norway. Arthritis Care Res (Hoboken). 2017;69:278-85. https://doi.org/10.1002/acr.22931.

32. Yang SK, Yun S, Kim JH, Park JY, Kim HY, Kim YH, et al. Epidemiology of inflammatory bowel disease in the Songpa-Kangdong district, Seoul, Korea, 1986-2005: a KASID study. Inflamm Bowel Dis. 2008;14:542-9. https://doi. org/10.1002/ibd.20310

33. Yazici H, Seyahi E, Hatemi G, Yazici Y. Behcet syndrome: a contemporary view. Nat Rev Rheumatol. 2018;14:107-19. https://doi.org/ 10.1038/nrrheum.2017.208.

34. Criteria for diagnosis of Behcet's disease. International Study Group for Behcet's Disease. Lancet. 1990;335:1078-80.

\section{Ready to submit your research? Choose BMC and benefit from:}

- fast, convenient online submission

- thorough peer review by experienced researchers in your field

- rapid publication on acceptance

- support for research data, including large and complex data types

- gold Open Access which fosters wider collaboration and increased citations

- maximum visibility for your research: over $100 \mathrm{M}$ website views per year

At BMC, research is always in progress.

Learn more biomedcentral.com/submissions 